\title{
Anti-arrhythmic Cardiac Phenotype Elicited by Chronic Intermittent Hypoxia Is Associated With Alterations in Connexin-43 Expression, Phosphorylation, and Distribution
}

OPEN ACCESS

Edited by:

Slava Berger,

Johns Hopkins Medicine,

United States

Reviewed by:

Aida Salameh,

Leipzig University, Germany

Candido Cabo,

The City University of New York,

United States

*Correspondence:

Jitka M. Zurmanova

jitka.zurmanova@natur.cuni.cz

Specialty section:

This article was submitted to

Diabetes,

a section of the journal

Frontiers in Endocrinology

Received: 24 August 2018 Accepted: 14 December 2018 Published: 25 January 2019

Citation:

Kohutova J, Elsnicova B, Holzerova K, Neckar J, Sebesta O, Jezkova J, Vecka M, Vebr P, Hornikova D, Szeiffova Bacova B, Egan Benova T, Hlavackova M, Tribulova N, Kolar F, Novakova $O$ and Zurmanova JM (2019) Anti-arrhythmic Cardiac

Phenotype Elicited by Chronic Intermittent Hypoxia Is Associated With Alterations in Connexin-43 Expression, Phosphorylation, and Distribution. Front. Endocrinol. 9:789. doi: 10.3389/fendo.2018.00789

\author{
Jana Kohutova ${ }^{1}$, Barbara Elsnicova ${ }^{1}$, Kristyna Holzerova ${ }^{2}$, Jan Neckar ${ }^{2}$, Ondrej Sebesta ${ }^{3}$, \\ Jana Jezkova ${ }^{1}$, Marek Vecka ${ }^{4}$, Pavel Vebr ${ }^{1}$, Daniela Hornikova ${ }^{1}$, \\ Barbara Szeiffova Bacova ${ }^{5}$, Tamara Egan Benova ${ }^{5}$, Marketa Hlavackova ${ }^{2}$, \\ Narcis Tribulova ${ }^{5}$, Frantisek Kolar ${ }^{2}$, Olga Novakova ${ }^{1,2}$ and Jitka M. Zurmanova ${ }^{1 *}$

\footnotetext{
${ }^{1}$ Department of Physiology, Faculty of Science, Charles University, Prague, Czechia, ${ }^{2}$ Developmental Cardiology, Institute of Physiology of the Czech Academy of Sciences, Prague, Czechia, ${ }^{3}$ Laboratory of Confocal and Fluorescence Microscopy, Faculty of Science, Charles University, Prague, Czechia, ${ }^{4} 4$ th Department of Internal Medicine, 1st Faculty of Medicine, Charles University, Prague, Czechia, ${ }^{5}$ Center of Experimental Medicine of the Slovak Academy of Sciences, Institute for Heart Research, Bratislava, Slovakia
}

Remodeling of the cellular distribution of gap junctions formed mainly by connexin-43 (Cx43) can be related to the increased incidence of cardiac arrhythmias. It has been shown that adaptation to chronic intermittent hypobaric hypoxia $(\mathrm{IHH})$ attenuates the incidence and severity of ischemic and reperfusion ventricular arrhythmias and increases the proportion of anti-arrhythmic n-3 polyunsaturated fatty acids ( $n-3$ PUFA) in heart phospholipids. Wistar rats were exposed to simulated $\mathrm{HH}(7,000 \mathrm{~m}, 8-$ h/day, 35 exposures) and compared with normoxic controls (N). Cx43 expression, phosphorylation, localization and n-3 PUFA proportion were analyzed in left ventricular myocardium. Compared to $\mathrm{N}, \mathbb{H H}$ led to higher expression of total $\mathrm{Cx} 43$, its variant phosphorylated at Ser368 [p-Cx43(Ser368)], which maintains "end to end" communication, as well as $\mathrm{p}-\mathrm{C} \times 43($ Ser364/365), which facilitates conductivity. By contrast, expression of non-phosphorylated Cx43 and p-Cx43(Ser278/289), attenuating intercellular communication, was lower in $\mathrm{HH}$ than in $\mathrm{N}$. $॥ \mathrm{HH}$ also resulted in increased expression of protein kinase $A$ and protein kinase $\mathrm{G}$ while casein kinase 1 did not change compared to $\mathrm{N}$. In $\mathrm{HH}$ group, which exhibited reduced incidence of ischemic ventricular arrhythmias, Cx43 and p-Cx43(Ser368) were more abundant at "end to end" gap junctions than in $\mathrm{N}$ group and this difference was preserved after acute regional ischemia (10 min). We further confirmed higher n-3 PUFA proportion in heart phospholipids after adaptation to $\mathrm{HH}$, which was even further increased by ischemia. Our results suggest that adaptation to $\mathrm{IHH}$ alters expression, phosphorylation and distribution of $\mathrm{Cx} 43$ as well as cardioprotective n-3PUFA proportion suggesting that the anti-arrhythmic phenotype elicited by $\mathrm{HH}$ can be at least partly related to the stabilization of the "end to end" conductivity between cardiomyocytes during brief ischemia.

Keywords: heart, chronic hypoxia, brief ischemia, arrhythmia, connexin-43, n-3 PUFA 


\section{INTRODUCTION}

Proper intercellular communication is essential for normal electrical activation of the myocardium and synchronized contraction of the heart for [review see (1)]. Various pathological states may lead to rhythm disturbances due to altered intercellular communication resulting in changes of conduction properties, expression and distribution of connexin-43 (Cx43), as a main component of gap junction (GJ) channels within ventricular myocardium $(2,3)$. Reduction of GJ number and conductance increases susceptibility to spontaneous and inducible ventricular arrhythmias both under control conditions and during ischemia and reperfusion $(\mathrm{I} / \mathrm{R})(4,5)$. Beside the number and properties of GJs, the location of $\mathrm{Cx} 43$ is also an important aspect contributing to arrhythmogenesis [reviewed by $(3,6,7)]$.

GJ permeability and conductivity are controlled by complex and multifactorial processes. These events are generally influenced by changes of intracellular environment under physiological and pathological conditions, e.g., $\mathrm{pH}$ and $\mathrm{Ca}^{2+}$ concentration (8-10). Specifically, the GJ conductivity is strongly influenced by $\mathrm{Cx} 43$ expression levels, its posttranslational modifications, protein-protein interactions, e.g., dimerization and interaction with Zona Occludens (ZO-1), Cx43 assembly and last but not least, the size of GJ plaques and their localization within cardiomyocytes [for review see (11)].

Under physiological conditions, GJs are predominantly located at the intercalated disks providing "end to end" conduction between neighboring cardiomyocytes. Small amounts of $\mathrm{Cx} 43$ are also found in the lateral plasma membrane away from the intercalated disks, allowing lateral conduction between cardiomyocytes (i.e., "side to side" conduction). Decreased expression of Cx43 as well as increased "side to side" conduction can cause deceleration and abnormal conduction leading to the generation of arrhythmias (12). On the other hand, ischemic preconditioning delayed electrical uncoupling and $\mathrm{Cx} 43$ de-phosphorylation (13).

Various modes of chronic hypoxia are well known to induce adaptive responses improving cardiac tolerance to major manifestations of acute I/R injury. It has been shown repeatedly that hearts adapted to chronic intermittent hypoxia (IHH) exhibit smaller infarct size, improved recovery of contractile function and, in particular, lower propensity to ventricular arrhythmias occurring during I/R insult (14-18). Importantly, we demonstrated previously that adaptation to $\mathrm{IHH}$ increases the abundance of antiarrhythmic n-3 polyunsaturated fatty acids (n-3 PUFA) in heart phospholipids (19). Although multiple factors have been shown to play a role in this form of cardioprotection $(20,21)$, the detailed mechanism is still unclear. To our knowledge, the potential involvement of $\mathrm{Cx} 43$ in the anti-arrhythmic effect of $\mathrm{IHH}$ has not been investigated.

Therefore, the goal of the present study was to assess the expression, phosphorylation and distribution of $\mathrm{Cx} 43$ as well as the expression of $\mathrm{Cx} 43$ upstream kinases in the myocardium of rats adapted to IHH. Moreover, the distribution of $\mathrm{Cx} 43 / \mathrm{p}-\mathrm{Cx} 43$ (Ser368) between "end to end" and "side to side" GJs as well the proportion of antiarrhythmic n-3 PUFA in heart phospholipids following brief ischemia were analyzed.

\section{MATERIALS AND METHODS}

\section{Animal Model}

Adult (8-week-old) male Wistar rats (250-280 g body weight) were exposed for 5 weeks to simulated $\mathrm{IHH}$ for 8 -h per day, 5 days per week. Barometric pressure $\left(P_{\mathrm{B}}\right)$ in the chamber was lowered stepwise, so that the level equivalent to an altitude of $7,000 \mathrm{~m}\left(P_{\mathrm{B}}=308 \mathrm{~mm} \mathrm{Hg}, 41 \mathrm{kPa} ; P_{2}=65 \mathrm{~mm} \mathrm{Hg}, 8.6 \mathrm{kPa}\right)$ was reached after 13 exposures. A control group was kept in the chamber under normoxic conditions equivalent to an altitude of $200 \mathrm{~m}\left(P_{\mathrm{B}}=742 \mathrm{~mm} \mathrm{Hg}, 99 \mathrm{kPa} ; \mathrm{PO}_{2}=155 \mathrm{~mm} \mathrm{Hg}, 20.7 \mathrm{kPa}\right)$ for the same period of time. Rats were fed by standard laboratory diet and kept at the 12/12-h light/dark cycle. Body weight of rats at the end of experiment increased to $407 \pm 54 \mathrm{~g}$ and $505 \pm 47 \mathrm{~g}$ in $\mathrm{IHH}$ and normoxic groups, respectively. The maintenance and handling of experimental animals was in accordance with the Guide for the Care and Use of Laboratory Animals published by the US National Institutes of Health (NIH Publication No. 85-23, revised 1996). The experimental protocol was approved by the Animal Care and Use Committee of the Institute of Physiology of the Czech Academy of Sciences.

\section{Regional Ischemia}

For immunolocalization studies and lipid composition analyses, subgroup of hearts from each group was subjected to acute ischemia as described previously (22). Briefly, animals were anesthetized (sodium pentobarbital, $60 \mathrm{mg} / \mathrm{kg}$ i.p.) and ventilated with room air at $68-70$ strokes/min (tidal volume of $1.2 \mathrm{ml} / 100 \mathrm{~g}$ body weight). A single-lead electrocardiogram was continuously recorded and subsequently analyzed by a custom-designed software. The rectal temperature was maintained between 36.5 and $37.5^{\circ} \mathrm{C}$ by a heated table throughout the experiment. Regional ischemia, the occlusion of the left coronary artery about $1-2 \mathrm{~mm}$ distal to its origin, was induced in open-chest rats after $15 \mathrm{~min}$ of stabilization by tightening the suture threaded through a polyethylene tube for $10 \mathrm{~min}$. The aim was to obtain ischemic myocardium with fully reversible injury. Hearts of sham-operated rats not subjected to ischemia (the suture beneath the artery was not ligated) served as controls. Rats were killed by cervical dislocation and their hearts were rapidly excised, washed in ice-cold saline and processed for further analyses.

\section{Analysis of Arrhythmias}

The incidence of ventricular arrhythmias during the 10-min ischemic episode was assessed as previously described (16). Premature ventricular complexes (PVCs) occurring as singles, salvos or tachycardia (a run of 4 or more consecutive PVCs) were counted separately. The incidence and duration of lifethreatening ventricular tachyarrhythmias, i.e., tachycardia and fibrillation, were also evaluated. 


\section{Immunofluorescence Study}

\section{Immunofluorescence Staining}

Six hearts from each experimental group were used for the immunofluorescence localization studies following a previously described protocol (23). Briefly, hearts were fixed by perfusion with $4 \%$ paraformaldehyde for $2 \mathrm{~min}$. Thereafter, hearts were immersed in buffered $4 \%$ formaldehyde for $2 \mathrm{~h}$ and subsequently incubated in $20 \%$ sucrose solution in PBS overnight. Separated left ventricles (LV) were cut transversally at one-third from apex and snap-frozen in liquid nitrogen. Longitudinal LV cryosections (6 $\mu \mathrm{m}$, prepared on cryostat Leica CM3050, Leicamicrosystems) were permeabilised in ice-cold methanol and then rinsed in $1 \%$ SDS as an antigen retrieval step. Nonspecific binding sites were blocked for $1 \mathrm{~h}$ at room temperature using $10 \%$ donkey serum in PBS containing $0.3 \%$ Triton X$100,1 \%$ BSA, $0.3 \mathrm{M}$ glycine and unconjugated donkey antirabbit IgG (Sigma-Aldrich). Sections were incubated with rabbit monoclonal antibody against $\mathrm{Cx} 43$ (Sigma-Aldrich) or with rabbit polyclonal antibody against p-Cx43(Ser368) (Santa Cruz). Primary antibodies were detected with donkey anti-rabbit IgG conjugated with Alexa Fluor 488 (Thermo Fisher Scientific). Sections were incubated with Alexa Fluor 647 conjugated wheat germ agglutinin (WGA, Thermo Fisher Scientific) to stain plasma membranes and the tubular system. Sections were then mounted in ProLong Gold Antifade Reagent containing the nuclei marker 4', 6-diamidino-2-phenylindole (DAPI) (Invitrogen) and stored at $4^{\circ} \mathrm{C}$.

\section{Image Acquisition}

Samples were examined using an inverted fluorescence microscope (Olympus IX81, Olympus, Tokyo, Japan) equipped with a MT20 mercury arc illumination unit, fully motorized stage (Märzhäuser Wetzlar, Corvus) and CCD camera (HamamatsuOrca C4742-80-12AG). Five ROIs from each experimental sample were acquired with 20x NA1.2 Plan-Apochromat lens with zero gain and $1 \times 1$ binning in $1344 \times 1024$ format, 16-bit. Filter combination for individual channels were set as follows: DAPI-triple-band set 69002-ET-DAPI/FITC/TexasRed ${ }^{\circledR}$ (Chroma Technology Corp.) ex. $350 \mathrm{~nm}$ (bandwidth $50 \mathrm{~nm}$ ) em. $457 \mathrm{~nm}$ (bandwidth $22 \mathrm{~nm}$ ), connexin 43 (Alexa Fluor 488) - fl. cube U-MWIBA3 (Olympus), ex. $477.5 \mathrm{~nm}$ (bandwidth $17.5 \mathrm{~nm}$ ) em. $530 \mathrm{~nm}$ (bandwidth $20 \mathrm{~nm}$ ), WGA (TMR)—fl. Cube U-MWIGA3 (Olympus), ex. $540 \mathrm{~nm}$ (band-width $10 \mathrm{~nm}$ ), em. $600 \mathrm{~nm}$ (bandwidth $25 \mathrm{~nm}$ ).

\section{Image Analysis}

Images were processed using FIJI open source software (24). Automatic process of quantification was performed by a sequence of four steps: (i) Image pre-processing: Raw images were calibrated according to objective characteristics and acquisition mode (see above), resulting in pixel size of $0.3225 \times 0.3225 \mu \mathrm{m}$. Uneven illumination was corrected using Background subtraction algorithm of FIJI ImageJ (created by Michael Castle and Janice Keller, https://imagej.net/Rolling_ Ball_Background_Subtraction) with rolling ball radius set to 50 pixels. (ii) Threshold setting: For each image, threshold was manually set to select all $\mathrm{Cx} 43$ particles. The area of individual
$\mathrm{Cx} 43$ particles was calculated and each particle was saved as ROI for further selection. (iii) Cx43 particles determination: WGA staining was used as marker of transversal/longitudinal orientation of the myocyte. A total of particles connecting myocytes in longitudinal course were distinguished as "end to end" type and junctions in transversal direction were defined as "side to side". (iv) "End to end" region: The percentage of "end to end" junction area to the total junction area was calculated. A custom script was written to allow semi-automation of the process.

\section{Lipid Analysis}

$\mathrm{LV}$ myocardium of normoxic and $\mathrm{IHH}$ rats subjected to brief ischemia and controls were frozen in liquid nitrogen and pulverized. Phospholipids were extracted from tissue samples according to the modified method of Folch et al. (25). Total phospholipids were separated by one-dimensional thinlayer chromatography using the solvent mixture hexane-etheracetic acid (80:20:3). For FA analyses, phospholipid spots were visualized under UV light after staining with $0.005 \% 2^{\prime}, 7^{\prime}$ dichlorofluorescein in methanol, scraped out and stored under nitrogen atmosphere at $-20^{\circ} \mathrm{C}$ until the next day when methyl esters were prepared. For FA methyl ester preparation, sodium methanolate was added to tubes with silica gel and tubes were incubated for $60 \mathrm{~min}$ at room temperature in the dark. Methyl esters were extracted with hexane. The extract was evaporated under a stream of nitrogen and stored at $-20^{\circ} \mathrm{C}$. Methyl esters were separated using the gas chromatograph CP $438 \mathrm{~A}$ (Chrompack, Middelburg, The Netherlands) with the middle polar column CP WAX $52 \mathrm{CB}(25 \mathrm{~m} \times 0.25 \mathrm{~mm}$ i.d. $)$. The oven temperature was programmed from 145 to $230^{\circ} \mathrm{C}$ at the rate of $2^{\circ} \mathrm{C} / \mathrm{min}$. Hydrogen was used as carrier gas. FA were identified using a mixture of FA methyl esters (26).

\section{SDS-PAGE and WB Analysis}

The tissue was handled as described previously (23). The LVs were isolated, weighed, and immediately frozen in liquid nitrogen. Frozen tissue was pulverized in liquid nitrogen and subsequently homogenized in homogenization buffer $[12.5 \mathrm{mM}$ TRIS, $2.5 \mathrm{mM}$ EGTA, $1 \mathrm{mM}$ EDTA, $250 \mathrm{mM}$ sucrose, $5 \mathrm{mM}$ DL-dithiothreitol (DTT), protease and phosphatase inhibitor cocktail mix (Roche/Sigma-Aldrich), pH 7.4]. Homogenates were diluted by urea buffer in the ratio 1:1 for proper solubilization ( $5 \mathrm{M}$ urea, $2 \mathrm{M}$ thiourea, $0.4 \mathrm{M}$ DTT, $10 \mathrm{mM}$ sodium pyrophosphate tetrabasic decahydrate) and subsequently protein concentrations were measured using the Bradford dye binding assay (Bio-Rad). Homogenates were aliquoted and stored at $-80^{\circ} \mathrm{C}$ for further analyses. Five homogenate samples from each group were separated by sodium dodecyl sulfate polyacrylamide gel electrophoresis on $10 \%$ bis-acrylamide gels at a constant voltage of $200 \mathrm{~V}$ using Mini-Protean TetraCell (Bio-Rad). The gel-resolved proteins were electro-transferred onto nitrocellulose membrane $(0.2 \mu \mathrm{m}$ pore size, Bio-Rad $)$ at a constant voltage of $100 \mathrm{~V}$ for $1 \mathrm{~h}$ using a Mini TransBlot Module (Bio-Rad). Subsequently, membranes were blocked with 5\% dry low fat milk in Tris-buffered saline with Tween 20 (TTBS) for $60 \mathrm{~min}$ at room temperature, washed 
in TTBS and individually incubated overnight at $4^{\circ} \mathrm{C}$ with the following primary antibodies: anti-GAPDH (Santa Cruz Biotechnology), anti-total-Cx43 (t-Cx43) (Sigma-Aldrich), antinon-phospho-Cx43 (np-Cx43) (ThermoFisher), anti-phosphoCx43 at Ser368 [p-Cx43(Ser368)] (Santa Cruz), anti-phosphoCx43 at Ser279/282 [p-Cx43(Ser279/282)] (Santa Cruz), antiphospho-Cx43 at Tyr265 p-Cx43(Tyr265) (Santa Cruz), antiprotein kinase A (PKA, Santa Cruz), anti-protein kinase G (PKG, Cell Signaling), anti-casein kinase 1 (CK1, Cell Signaling). Subsequently, membranes were washed in TTBS and incubated with the appropriate secondary antibodies: either anti-rabbit (GE Healthcare Amersham) or anti-mouse immunoglobulins (Thermo Fisher Scientific) conjugated with HRP, visualized by chemiluminescence (DuraSignal) using LAS-4000 imaging system (Genetica, Fujifilm) and quantified using Quantity One Software (Bio-Rad). The same amount of protein was loaded on the gels in the range of 10 to $30 \mu \mathrm{g}$ per lane. All samples from each group were always run on the same gel and quantified on the same membrane. Glyceraldehyde 3phosphate dehydrogenase and actin expression was used as loading control. Each sample was analyzed in duplicate in at least four gels. The results were normalized to total protein amount.

\section{Mass Spectrometry for Myocardial Cx43 Phosphorylation}

Five hearts from normoxic and $\mathrm{IHH}$ groups were powdered and solubilized in 4\% SDS, $10 \mathrm{mM}$ TCEP, $40 \mathrm{mM}$ chloroacetamide and $100 \mathrm{mM}$ Tris, $\mathrm{pH} 7.5$. Samples were kept $5 \mathrm{~min}$ at $95^{\circ} \mathrm{C}$ and sonicated 4 -times for $20 \mathrm{~s}$ each. Samples were precipitated by addition of 4 volumes of cold acetone overnight $\left(-20^{\circ} \mathrm{C}\right)$. The pellet was resuspended in 10\% TFE (trifluorethanol) and $100 \mathrm{mM}$ ammonium bicarbonate. Samples $(500 \mu \mathrm{l})$ containing $2 \mathrm{mg}$ of proteins were cleaved with trypsin overnight (27). Phosphopeptides were enriched according to Humphrey et al. (28). LC-MS was done on OrbitrapFusion coupled with NanoLC Dionex Ultimate 3000RS. A $50 \mathrm{~cm}$ Thermoeasy nano column connected in combination with upstream placed trap column 300 um ID, $5 \mathrm{~mm}$ length was used for separation. Two hours separation gradient was used. Data were searched with MaxQuant (29) software against latest Uniprot Rattus Norvegicus database with phospho STY like variable modification. Data from MaxQuant were further processed with Perseus Software (30). Quantitative values for identified phosphopeptides were subjected to further statistical analysis.

\section{Statistical Analysis}

The statistical differences between the groups were determined by Two Way ANOVA with Bonfferoni post-test for immunofluorescence and fatty acid analyses. The incidence of tachyarrhythmias was examined by Fisher's exact test. The duration of tachyarrhythmias and the number of PVCs were compared by the Mann-Whitney $U$ test. Unpaired $t$ test was used for all other experiments. Values of $p<0.05$ were

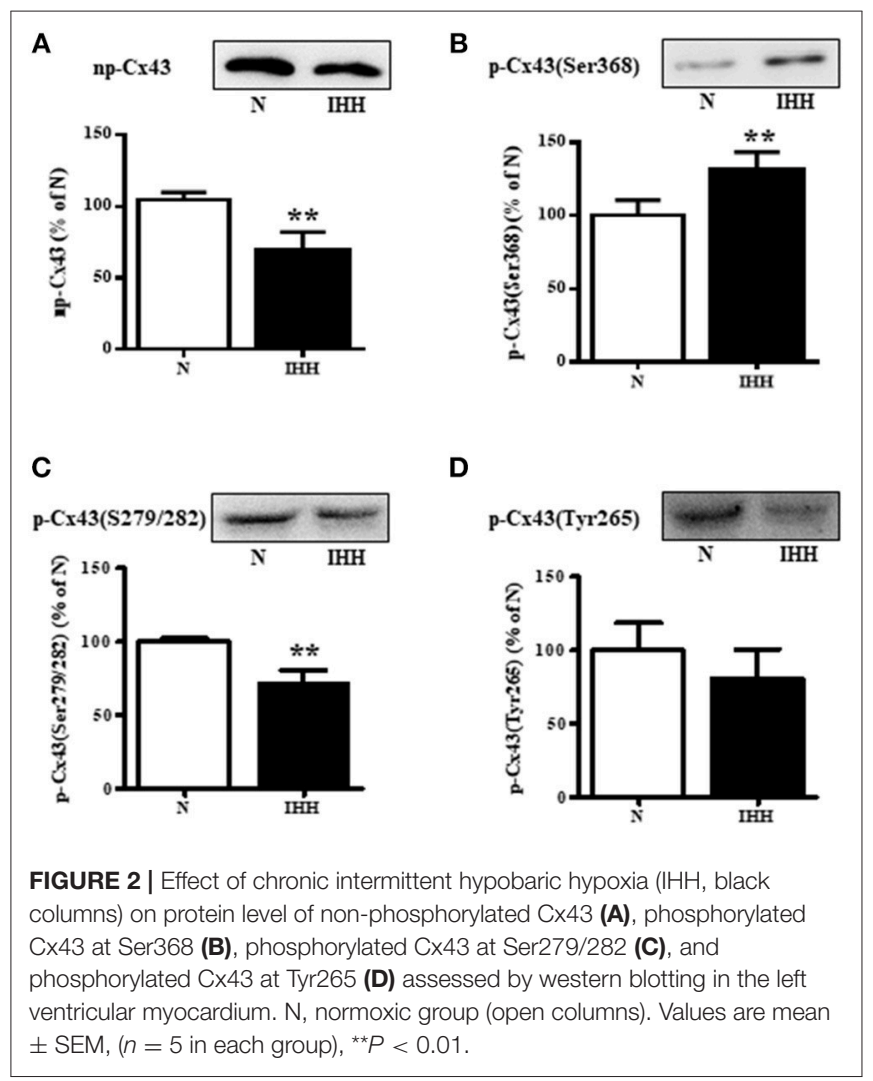

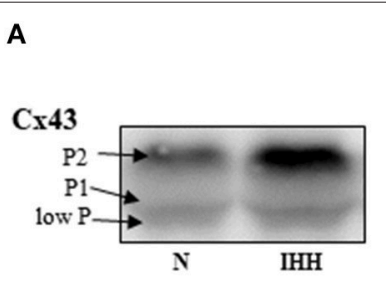

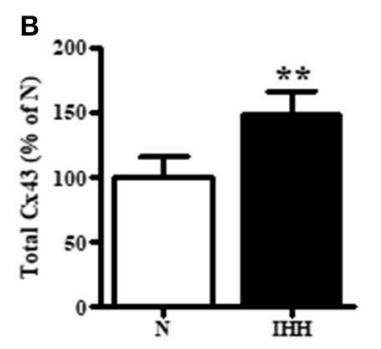

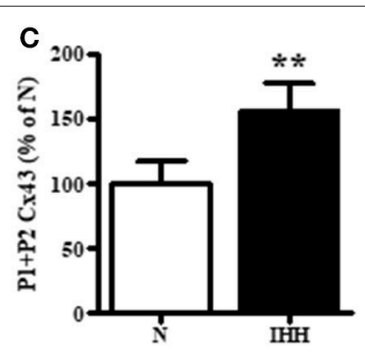

FIGURE 1 | Effect of chronic intermittent hypobaric hypoxia ( $\mathrm{HH}$, black columns) on expression of total $\mathrm{Cx} 43$ (B) and its high-phosphorylated forms (P1+P2 Cx43) (C) compared with normoxic group ( $N$, open columns). The representative image of western blotting is shown (A). Values are mean $\pm \mathrm{SEM}$, $(n=5$ in each group), ${ }^{\star *} p<0.01$. 
considered statistically significant. Data were expressed as a mean \pm SEM

\section{RESULTS}

\section{Myocardial Expression of Total Cx43 and Its Phosphorylated Status}

Total Cx43 expression (t-Cx43) increased by $48 \%$ (Figure 1B) and, in parallel, the level of high-phosphorylated $\mathrm{P} 1+\mathrm{P} 2$ forms of $\mathrm{t}-\mathrm{Cx} 43$ also increased by $56 \%$ (Figures 1A,C) in $\mathrm{IHH}$ myocardium compared to normoxic group. Importantly, using specific anti-np-Cx43 antibody we demonstrated a decrease of $\mathrm{np}-\mathrm{Cx} 43$ expression by $30 \%$ in IHH group (Figure 2A). Furthermore, specific antibodies for phosphorylated sites showed that the p-Cx43(Ser368), which increases GJ communication, was elevated in the IHH group by $30 \%$ compared to normoxic group (Figure 2B). By contrast, phosphorylation at $\mathrm{p}-\mathrm{Cx} 43(\mathrm{Ser} 279 / 282)$, which attenuates intercellular communication, decreased by $27 \%$ after $\mathrm{IHH}$ (Figure 2C). The phosphorylation at p-Cx43(Tyr265), which may contribute to internalization or distribution of $\mathrm{Cx} 43$, did not change (Figure 2D). Additionally, MS analyses revealed that IHH induced increased phosphorylation of p-Cx43(Ser364, Ser365) and confirmed the increase of p-Ser368 (Figures 3A-C, respectively).

\section{Expression of Cx43 Upstream Kinases}

With respect to upstream kinases affecting $\mathrm{Cx} 43$ function, we showed that in the IHH group, the expression of PKA and PKG increased by 33 and 19\%, respectively (Figures $4 \mathbf{A}, \mathbf{B}$ ), whereas there was no change in the expression of CK1 compared to normoxic group (Figure 4C).

\section{Redistribution of t-Cx43 and p-Cx43(Ser368) to "end to end" Junctions}

Quantitative immunofluorescence analysis revealed that t$\mathrm{C} \times 43$ was located predominantly at "end to end" junctions (Figures 5A,B). IHH increased the area of t-Cx43 at "end to end" junctions by $10 \%$ compared to normoxic group (Figures $\mathbf{5 A}, \mathbf{B}$ ). Similarly, p-Cx43(Ser368) predominantly localized at "end to end" junctions under normoxia (Figures 5C,D), was increased at this location by $10 \%$ after IHH (Figures 5C,D). Whereas, 10min ischemia decreased the proportion of $\mathrm{t}-\mathrm{Cx} 43$ at "end to end" junctions (Figures 5A,B), the significant difference in $\mathrm{p}$ Cx43(Ser368) localization between IHH and N groups persisted (Figures 5C,D). Because the area of "end to end" junctions was calculated as a percentage of the total junctions, the "side to side" area changed reciprocally.

\section{Fatty Acid Composition of Total Phospholipids}

Subsequently, we also analyzed the effect of IHH and 10-min ischemia on PUFA proportion in phospholipids (Figure 6). IHH increased the proportion of docosahexaenoic acid (22:6n-3) and total n-3 PUFA, which was accompanied by a decrease of linoleic acid (18:2n-6). The proportion of arachidonic acid (20:4n-6) did not change. While ischemia had no influence on normoxic group, it significantly enhanced n-3 PUFA proportion in IHH group by a further 13\% due to the rise of docoshexaenoic acid (Figure 6).

\section{Ischemic Ventricular Arrhythmias}

The incidence of ventricular tachyarrhythmias during 10-min coronary occlusion was significantly lower in rats adapted to IHH than in their normoxic counterparts (Figure 7A). IHH also significantly reduced total duration of ventricular tachyarrhythmias (Figure 7B) as well as the total number of premature ventricular complexes occurring as singles, salvos or tachycardia (Figure 7C).

\section{DISCUSSION}

In the present study we demonstrated the association of antiarrhythmic phenotype of IHH rats with increased myocardial $\mathrm{t}-\mathrm{Cx} 43$ protein level and its phosphorylation, as well as enhanced location of both t-Cx43 and p-Cx43(Ser368) at "end to end" junctions; the latter effect persisted even after 10-min ischemia. Importantly, brief ischemia further increased the already high proportion of n-3 PUFA in membrane phospholipids induced by IHH. This observation is in agreement with enhanced endogenous protection against life-threatening I/R arrhythmias described earlier in the same experimental model of $\mathrm{IHH}$ $(15,16,31)$.

The elevated protein expression of $\mathrm{t}-\mathrm{Cx} 43$ and its phosphorylated forms due to $\mathrm{IHH}$ is consistent with studies suggesting that protein up-regulation of myocardial $\mathrm{Cx} 43$ is linked to protection from arrhythmias [for review see (7)]. It is noteworthy that our experimental model of chronic IHH differs from models of intermittent hypoxia consisting of multiple cycles of brief severe hypoxia and reoxygenation episodes used to simulate obstructive sleep apnoea (OSA) syndrome as an important risk factor of cardiovascular diseases. It has been shown that OSA results in reduction and remodeling of myocardial $\mathrm{Cx} 40$ and $\mathrm{Cx} 43$, which may contribute to arrhythmogenic substrate (32). Other maladaptive responses resulting in increased propensity to arrhythmias, such as hypertension (33), altered thyroid status (34), and doxorubicininduced cardiomyopathy (35) are also accompanied by down-regulation of $\mathrm{Cx} 43$. Similarly, conditional Cx43 knockout facilitates pro-arrhythmia state and contributes to cardiac contractile dysfunction $(1,36,37)$.

We have further demonstrated that IHH affected the phosphorylation status of $\mathrm{Cx} 43$ at four sites: Ser364, Ser365, Ser368, and Ser279/282 belonging to upstream PKA, PKC, and MAPK, respectively. Additionally, protein kinase B/Akt, $\mathrm{CK} 1$, and $\mathrm{v}$-Src tyrosine kinase are involved in controlling Cx43 phosphorylation [reviewed by $(38,39)$ ]. Post-translational modifications of $\mathrm{Cx} 43$ play an important role in the regulation of GJ assembly, conductivity and permeability, depending on the phosphorylation site and the executing upstream kinases (40).

PKA upregulation by IHH was accompanied by PKAtargeted phosphorylation of $\mathrm{Cx} 43$ at Ser364, Ser365 which accelerates Cx43 assembly and conductivity $(41,42)$. Moreover, phosphorylation at $\mathrm{Cx} 43$ (Ser365) is considered as a gate-keeper of these events (42). On the other hand, IHH upregulated PKG 

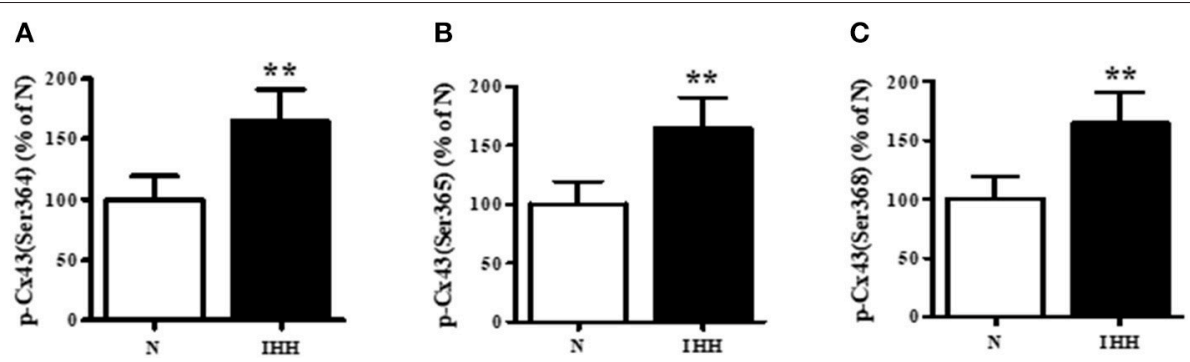

FIGURE 3 | Effect of chronic intermittent hypobaric hypoxia (IHH, black columns) on phosphorylation of Cx43 at Ser364 (A), Ser365 (B), and Ser368 (C) assessed by Mass Spectrometry in left ventricular myocardium. N, normoxic group (open columns). Values are mean $\pm \mathrm{SEM}$, ( $n=5$ in each group), ${ }^{\star \star} P<0.01$.

A

PKA
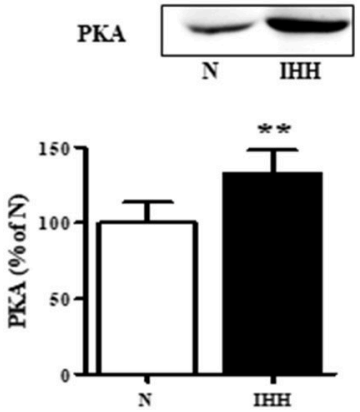

B

PKG

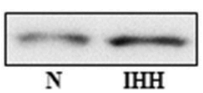

C

CKl

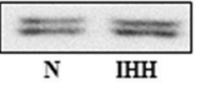

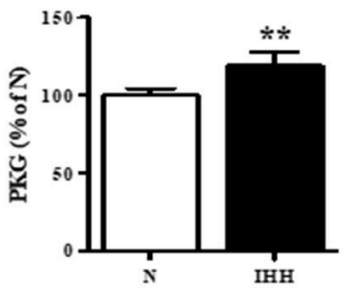

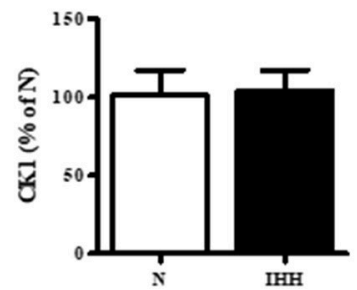

FIGURE 4 | Effect of chronic intermittent hypobaric hypoxia (IHH, black columns) on protein expression of Cx43 upstream protein kinases: protein kinase A (PKA) (A), protein kinase G (PKG) (B), and casein-kinase 1 (CK1) (C) assessed by western blotting in left ventricular myocardium. N, normoxic group (open columns). Values are mean \pm SEM, ( $n=5$ in each group), ${ }^{* \star} P<0.01$.

which has been shown to attenuate conductivity (43). Contrary to that, neither the expression of CK1 nor phosphorylation of targeting phospho-sites at Ser325/Ser328/Ser330 was affected by IHH suggesting that $\mathrm{IHH}$ did not influence the main pathway responsible for the redistribution of $\mathrm{Cx} 43$ from the plasma membrane into GJs $(44,45)$. Thus enhancement of both PKA and PKG might be involved in increased Cx43 trafficking, assembly and moderation of conductivity induced by $\mathrm{IHH}$.

Both MS analyses and western blotting of IHH myocardium revealed increased phosphorylation of $\mathrm{Cx} 43$ (Ser368) which is mostly attributed to $\mathrm{PKC} \varepsilon$ (46). In line with this view, Hlaváčková et al. (47) reported an increased $\mathrm{p}-\mathrm{PKC} \varepsilon(\operatorname{Ser} 729) / \mathrm{PKC} \varepsilon$ ratio indicating enhanced activation of the enzyme under $\mathrm{IHH}$ conditions. Importantly, the increased level of p-Cx43(Ser368) by $\mathrm{PKC} \varepsilon$, stabilizes GJs in intercalated discs, prevents lateralization and attenuates $\mathrm{Cx} 43$ channel conductivity (48). Accordingly it prevents inducible ventricular fibrillation (49). PKCE-related phosphorylation of Cx43 at Ser368 may be additionally finetuned by suppression of Cx43 phosphorylation at Tyr265 and Ser279/282 sites; the latter was observed in the present study. Thus, $\mathrm{PKC} \varepsilon$ activation can be implicated in $\mathrm{IHH}$-related suppression of arrhythmia susceptibility, likely due to rectifying conductance in "end to end" junctions and reducing conduction in favor of electrical stability.

As mentioned before, we found that the level of MAPKmediated p-Cx43(Ser279/282), possessing inhibiting effect on
GJs, decreased in IHH group. This suggests that IHH attenuates MAPK-controlled internalization and subsequent degradation of $\mathrm{Cx} 43$ by endocytosis and thus stabilization of $\mathrm{Cx} 43$ channel gating and conductivity of GJs $(40,50)$. Besides that, phosphorylation of Cx43(Tyr265), mediated by v-Src, did not change in $\mathrm{IHH}$ myocardium compared to normoxic controls. It was shown that the $\mathrm{v}$-Src phosphorylation of $\mathrm{Cx} 43$ at Tyr247/Tyr265 inhibits GJ communication and may cause their disassembly (51).

It has been reported that Akt activity controls GJ stability and participates in formation of larger and stable GJs (52). Direct inhibition of Akt leads to the loss of GJ by internalization. Phosphorylation of Cx43 at S373 by Akt appears to control GJ size through inhibition of the interaction of Cx43 with ZO-1 (53). Interestingly, it has been demonstrated that under conditions of injury (wound healing) or growth factor treatment, Cx43 becomes sequentially phosphorylated by Akt (5-15 min post treatment on p-Ser373), MAPK (at 15-30 min on p-Ser279/S282) and $\mathrm{v}$-Src (at $30 \mathrm{~min}$ extending for hours on p-Tyr247) resulting in sequential changes in GJs, including increased size followed by inhibition of GJ communication and their internalization from the plasma membrane (38). Importantly, we have documented highly activated Akt after 10-min ischemia in chronically hypoxic heart (54).

In line with a number of previous studies, we observed decreased incidence and duration of ventricular 

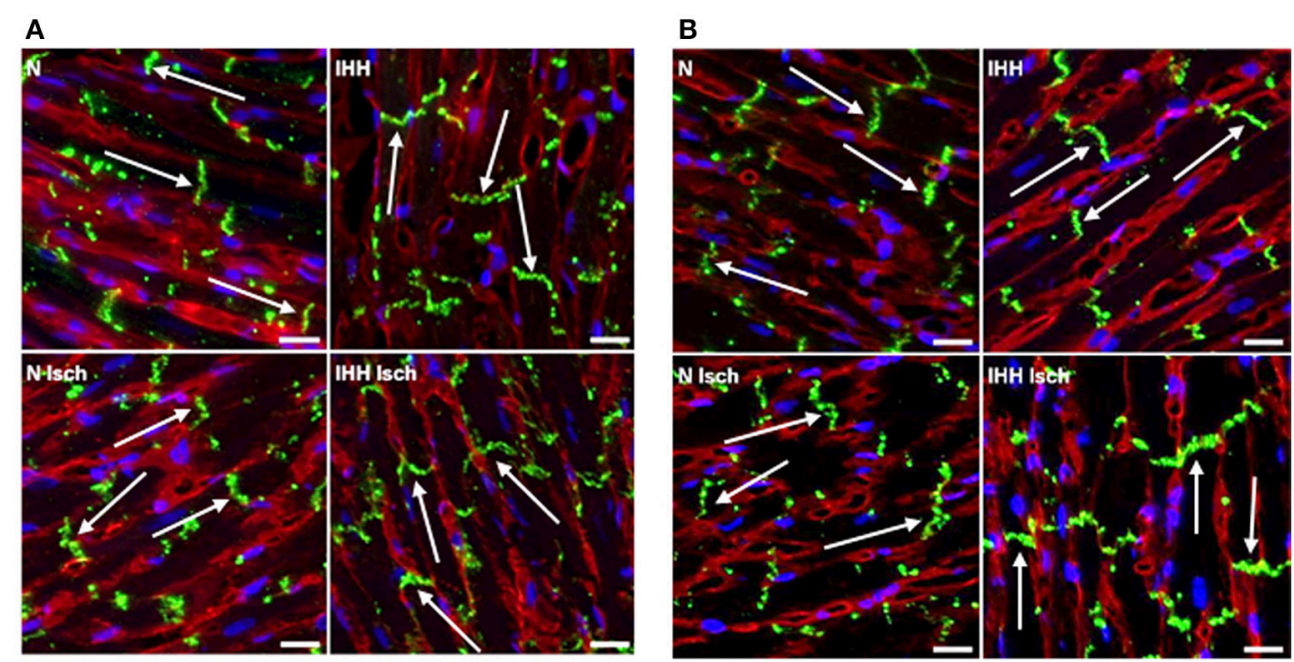

C

D
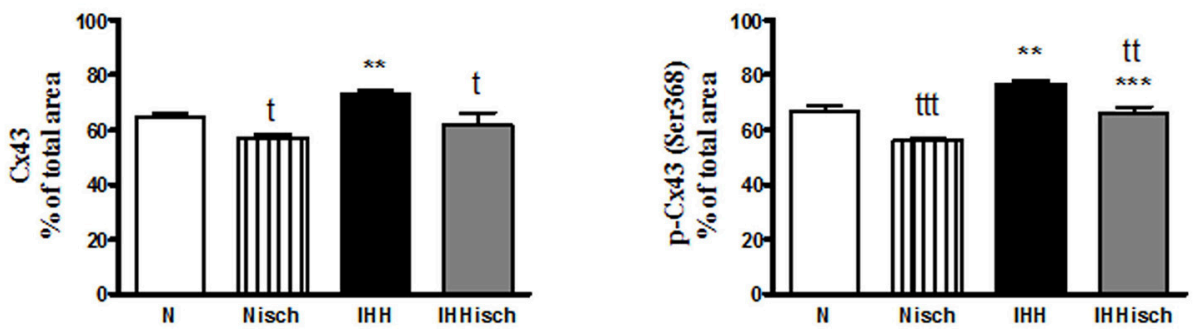

FIGURE 5 | Effect of chronic intermittent hypobaric hypoxia $(\mathrm{IHH})$ on distribution of total $\mathrm{Cx} 43$. The representative micrograph of longitudinal cryosections demonstrates distribution of t-Cx43 (A) and p-Cx43(Ser368) (C) after 10-min regional ischemia in normoxic (N Isch) and hypoxic (IHH Isch) left ventricular myocardium compared to control groups not subjected to ischemia $(\mathrm{N}, \mathrm{IH})$. The green color corresponds to specific $\mathrm{Cx} 43$ staining, red color represents sarcolemma (counterstained by WGA) and the blue color indicates nuclei DAPI staining. Note the positive Cx43 staining (arrows) located predominantly at the intercalated discs, i.e., "end to end" junctions of the cardiomyocytes. The proportion of t-Cx43 and p-Cx43(Ser368) at "end to end" junctions in normoxic (N) and hypoxic (IHH) groups under control conditions and after ischemia (Isch) (B,D) is expressed as a percentage of total junctions. Values are mean \pm SEM, ( $n=6$ in each group), ${ }^{*}$ vs. corresponding normoxic group; ${ }^{\mathrm{t}}$ vs. corresponding non-ischemic group; ${ }^{\mathrm{t}} P \leq 0.05,{ }^{\star \star} / \mathrm{tt} P \leq 0.01,{ }^{\star \star \star} / \mathrm{ttt} P \leq 0.001$. Scale bar represents $20 \mu \mathrm{m}$.

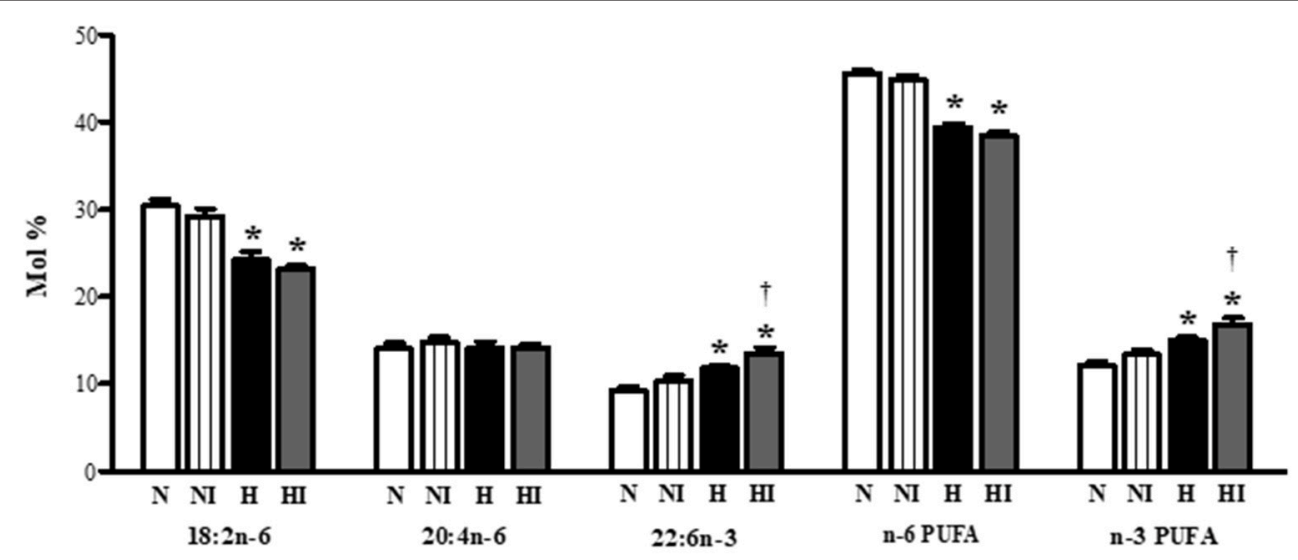

FIGURE 6 | Effect of chronic intermittent hypobaric hypoxia on main polyunsaturated fatty acids [linoleic acid (18:2n-6), arachidonic acid (20:4n-6),

docosahexaeonic acid (22:6n-3)], total n-6 PUFA and total n-3 PUFA proportion in total phospholipids in the left ventricular myocardium of normoxic (N) and hypoxic $(\mathrm{H})$ rats under control (non-ischemic) conditions and after 10-min regional ischemia ( $\mathrm{Nl}$ and $\mathrm{HI}$, respectively. Values are mean $\pm \mathrm{SEM}$, $(n=7$ in each group), ${ }^{\star} P<0.05$ vs. normoxia, ${ }^{\dagger} P<0.05$ vs. corresponding control group. 

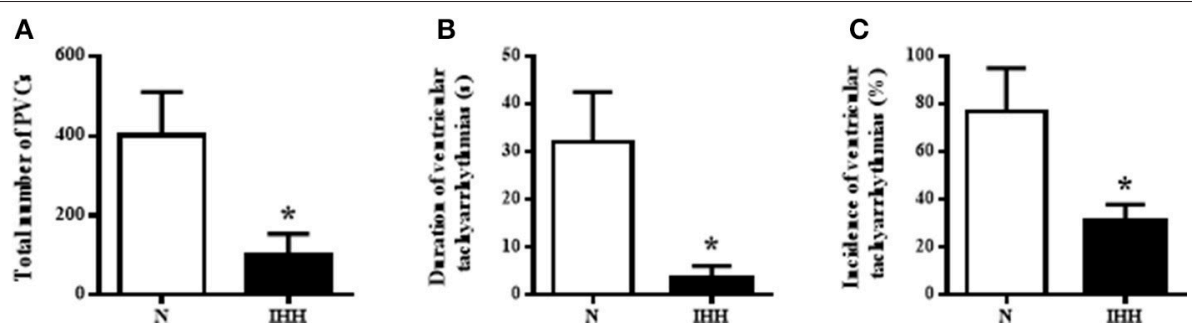

FIGURE 7 | Effect of chronic intermittent hypobaric hypoxia ( $\mathrm{HH}$, black columns) on the incidence of ventricular tachyarrhythmias (tachycardia and fibrillation) (A), total duration of ventricular tachyarrhythmias (B) and total number of premature ventricular complexes (PVCs) occurring as singles, salvos and tachycardia (C) during 10-min regional ischemia. N, normoxic group (open columns). Values are mean $\pm \mathrm{SEM},\left(n=13\right.$ in each group), ${ }^{\star} P<0.05$.

tachyarrhythmias as well as reduced total number of premature ventricular complexes during 10-min ischemia in rats adapted to IHH. This IHH-induced anti-arrhythmic protection was associated with, changes in $\mathrm{Cx} 43$ distribution. Quantitative image analysis revealed slightly but significantly increased proportion of both $\mathrm{t}-\mathrm{Cx} 43$ and $\mathrm{p}-\mathrm{Cx} 43$ (Ser368) at "end to end" GJs in IHH myocardium. Whereas, 10-min ischemia basically decreased the proportion of $\mathrm{Cx} 43$ at "end to end" junctions, the difference in $\mathrm{p}$-Cx43(Ser368) localization between $\mathrm{IHH}$ and $\mathrm{N}$ groups persisted. This can be considered as a benefit of $\mathrm{IHH}$ adaptation that may participate in the decreased susceptibility of hearts to ischemia-induced arrhythmias. In line with this, anti-arrhythmic ischemic preconditioning prolonged the time to plateau in electrical uncoupling, translocation of Cx43 from GJs to the cytosol and dephosphorylation of Cx43 in rat hearts (13). On the other hand, abnormal Cx43 lateralization, due to prolonged ischemia, was accompanied by Cx43 dephosphorylation (55). Furthermore, reduced overall expression of $\mathrm{Cx} 43$ as well as increased lateralization accelerated the onset, incidence, frequency, and duration of ventricular arrhythmias after coronary artery occlusion (56). High lateral "side to side" GJ conductance increased the susceptibility to conduction block providing a substrate for arrhythmias $(6,57-59)$. Based on the above, we can assume that increased phosphorylation of PKA and PKC target phospho-sites of Cx43 accompanied by the decrease in MAPK targeting Cx43 inhibiting sites, as well the decrease of lateralization, contributes to $\mathrm{IHH}$ elicited anti-arrhythmic phenotype possibly based on moderating permeability and rectifying "end to end" conductivity.

In general, cardioprotective action of n-3 PUFA has been widely documented [reviewed by $(60,61)]$. Their antiarrhythmic effect may depend on the integrity and lipid composition of membranes, affecting conductivity e.g., by reduction of membrane electrical excitability and activity of voltage-dependent sodium channels in cardiomyocytes $(62,63)$ as well as by modulation of calcium channels (64) and possibly through shortening of the action potential (65). It has been also reported that n-3 PUFA improved electrical remodeling, increased Cx43 expression and reduced arrhythmias in hypertensive rat hearts $(66,67)$ suggesting tight relation between anti-arrhythmic effect of $\mathrm{Cx} 43$ and n-3 PUFA. We have shown previously that $\mathrm{IHH}$ increased the proportion of n-3 PUFA in heart phospholipids (19). The n-3 PUFA dietary supplementation of rats during adaptation to $\mathrm{IHH}$ resulted in a cumulative anti-arrhythmic effect which almost completely eliminated ventricular arrhythmias induced by I/R insult (68). The present study showed that brief ischemia even further enhanced the already high proportion of n-3 PUFA in membrane phospholipids of IHH hearts, which is in line with increased p-Cx43(Ser368) level at "end to end" GJs.

In conclusion, we have demonstrated that chronic $\mathrm{IHH}$, which induces strong protection against arrhythmias occurring during acute I/R insult, is associated with increased expression, phosphorylation and redistribution of myocardial $\mathrm{Cx} 43$ as well as with increased anti-arrhythmic n-3 PUFA proportion in heart phospholipids persisting after brief ischemia.

\section{ETHICS STATEMENT}

The maintenance and handling of experimental animals was in accordance with the Guide for the Care and Use of Laboratory Animals published by the US National Institutes of Health (NIH Publication No. 85-23, revised 1996). The experimental protocol was approved by the Animal Care and Use Committee of the Institute of Physiology of the Czech Academy of Sciences.

\section{AUTHOR CONTRIBUTIONS}

JK performed major part of experiments, interpreted data, drafted manuscript. BE image quantitative analyses. $\mathrm{KH}$ performed experiments. JN hypoxic model, performed experiments. OS image quantitative analyses. JJ fatty acid analyses. MV fatty acid analyses. PV, BS, TE and MH performed experiments. DH performed experiments, prepared images. NT performed experiments, edited manuscript. FK hypoxic model, edited manuscript. ON fatty acid analyses-interpreted data, edited manuscript, and finalized manuscript. JZ experimental design, performed experiments, interpreted data, finalized manuscript.

\section{ACKNOWLEDGMENTS}

The authors would like to thank Dr. Peter Van der Ven for constructive criticism of the manuscript. This work has been supported by the Charles University Grant Agency (GAUK 
940216) and SVV-260434/2018 (Charles University in Prague), Grant Agency of Czech Republic (17-07748S, 16-12420Y), VEGA $2 / 0160 / 15$, VEGA 2.0076/16. Microscopy was performed in the Laboratory of Confocal and Fluorescence Microscopy

\section{REFERENCES}

1. Saffitz JE, Yamada KA. Do alterations in intercellular coupling play a role in cardiac contractile dysfunction? Circulation (1998) 97:630-32. doi: 10.1161/01.CIR.97.7.630

2. Severs NJ, Bruce AF, Dupont E, Rothery S. Remodelling of gap junctions and connexin expression in diseased myocardium. Cardiovasc Res. (2008) 80:9-19. doi: $10.1093 / \mathrm{cvr} / \mathrm{cvn} 133$

3. Fontes MSC, Veen TAB, Van Bakker JMT, De Rijen HVM, Van. Functional consequences of abnormal Cx43 expression in the heart. BBA - Biomembranes (2012) 1818:2020-9. doi: 10.1016/j.bbamem.2011.07.039

4. Danik SB, Liu F, Zhang J, Suk HJ, Morley GE, Fishman GI, et al. Modulation of cardiac gap junction expression and arrhythmic susceptibility. Circulat Res. (2004) 95:1035-41. doi: 10.1161/01.RES.0000148664.33695.2a

5. Sanchez J, Rodriguez-Sinovas A, Fernandez-Sanz C, Ruiz-Meana M, GarciaDorado D. Effects of a reduction in the number of gap junction channels or in their conductance on ischemia-reperfusion arrhythmias in isolated mouse hearts. Am J Physiol Heart Circulat Physiol. (2011) 301:2442-53. doi: 10.1152/ajpheart.00540.2011

6. Tribulova N, Knezl V, Okruhlicova L, Slezak J. Myocardial gap junctions: targets for novel approaches in the prevention of life-threatening cardiac arrhythmias. Physiol Res Acad Scientiarum Bohemoslovaca (2008) 57 (Suppl. 2):1-13.

7. Tribulova N, Szeiffova Bacova B, Benova T, Viczenczová C. Can we protect from malignant arrhythmias by modulation of cardiac cell-to-cell coupling? J. Electrocardiol. (2015) 48:434-40. doi: 10.1016/j.jelectrocard.2015.02.006

8. Ek-Vitorín JF, Calero G, Morley GE, Coombs W, Taffet SM, Delmar M. pH regulation of connexin43: molecular analysis of the gating particle. Biophys J. (1996) 71:1273-84. doi: 10.1016/S0006-3495(96)79328-1

9. Peracchia C. Chemical gating of gap junction channels: roles of calcium, pH and calmodulin. Biochim Biophys Acta (2004) 1662:61-80. doi: 10.1016/j.bbamem.2003.10.020

10. Cascio W, Yang $\mathrm{H}$, Muller-Borer $\mathrm{B}$, Johnson $\mathrm{T}$. Ischemia-induced arrhythmia: the role of connexins, gap junctions, and attendant changes in impulse propagation. J Electrocardiol. (2005) 38:55-9. doi: 10.1016/j.jelectrocard.2005.06.019

11. Leithe E, Mesnil M, Aasen T. The connexin 43 C-terminus: a tail of many tales. Biochim Biophys Acta Biomemb. (2018) 1860:48-64. doi: 10.1016/j.bbamem.2017.05.008

12. Verheule S, Tuyls E, Gharaviri A, Hulsmans S, Van Hunnik A, Kuiper M, et al. Loss of continuity in the thin epicardial layer because of endomysial fibrosis increases the complexity of atrial fibrillatory conduction. Circulation (2013) 6:202-11. doi: 10.1161/CIRCEP.112.975144

13. Jain SK, Schuessler RB, Saffitz JE. Mechanisms of delayed electrical uncoupling induced by ischemic preconditioning. Circulat Res. (2003) 92:1138-44. doi: 10.1161/01.RES.0000074883.66422.C5

14. Meerson F, Ustinova E, Manukhina E. Prevention of cardiac arrhythmias by adaptation: regulatory mechanisms and cardiotropic effect. Biomed Biochim Acta (1989) 48:583-8.

15. Asemu G, Papousek F, Ostadal B, Kolar F. Adaptation to high altitude hypoxia protects the rat heart against ischemia- induced arrhythmias. involvement of mitochondrial KATP channel. J Mol Cell Cardiol. (1999) 31:1821-31. doi: 10.1006/jmcc.1999.1013

16. Asemu G, Neckar J, Szarszoi O, Papousek F, Ostadal B, Kolar F. Effects of adaptation to intermittent high altitude hypoxia on ischemic ventricular arrhythmias in rats. Physiol Res. (2000) 49:597-606.

17. Zhang Y, Zhong N, Zhou Z. Estradiol potentiates antiarrhythmic and antioxidative effects of intermittent hypoxic rat heart. Acta Pharmacol Sin. (2000) 21:609-12.

18. Naryzhnaya N, Mukhamedzyanov A, Lasukova T, Maslov L. Involvement of autonomic nervous system in antiarrhythmic effect of co-financed by the European Regional Development Fund and the state budget of the Czech Republic. Project no. CZ.1.05/4.1.00/16.0347 and CZ.2.16/3.1.00/21515 and supported by the Czech-BioImaging large RI project LM2015062.

intermittent hypobaric hypoxia. Bull Exp Biol Med. (2017) 163:299-301. doi: 10.1007/s10517-017-3789-8

19. Jezkova J, Novakova O, Kolar F, Tvrzicka E, Neckar J, Novak F. Chronic hypoxia alters fatty acid composition of phospholipids in right and left ventricular myocardium. Mol Cell Biochem. (2002) 232:49-56. doi: 10.1023/A:1014889115509

20. Ostadal B, Kolar F. Cardiac adaptation to chronic high-altitude hypoxia: beneficial and adverse effects. Respir Physiol Neurobiol. (2007) 158:224-36. doi: 10.1016/j.resp.2007.03.005

21. Mallet R, Manukhina E, Ruelas S, Caffrey J, Downey H. Cardioprotection by intermittent hypoxia conditioning: evidence, mechanisms, and therapeutic potential. Am J Physiol Heart Circ Physiol. (2018) 315:216-32. doi: 10.1152/ajpheart.00060.2018

22. Neckar J, Svatonova A, Weissova R, Drahota Z, Zajickova P, Brabcova I, et al. Selective replacement of mitochondrial DNA increases the cardioprotective effect of chronic continuous hypoxia in spontaneously hypertensive rats. Clin Sci. (2017) 131:865-81. doi: 10.1042/CS20170083

23. Waskova-Arnostova P, Elsnicova B, Kasparova D, Hornikova D, Kolar F, Novotny J, et al. Cardioprotective adaptation of rats to intermittent hypobaric hypoxia is accompanied by the increased association of hexokinase with mitochondria. J Appl Physiol. (2015) 119:1487-93. doi: 10.1152/japplphysiol.01035.2014

24. Schindelin J, Arganda-Carreras I, Frise E, Kaynig V, Longair M, Pietzsch T, et al. Fiji: an open source platform for biological image analysis. Nat Methods (2012) 9:676-82. doi: 10.1038/nmeth.2019.Fiji

25. Folch J, Lees M, Sloane Stanley G. A simple method for the isolation and purification of total lipides from animal tissues. J Biol Chem. (1957) 55:9991033. doi: 10.1016/j.ultrasmedbio.2011.03.005

26. Tvrzicka E, Vecka M, Stankova B, Zak A. Analysis of fatty acids in plasma lipoproteins by gas chromatography-flame ionization detection: quantitative aspects. Anal Chim Acta (2002) 465:337-50. doi: 10.1016/S0003-2670(02)00396-3

27. Erban T, Harant K, Chalupnikova J, Kocourek F, Stara J. Beyond the survival and death of the deltamethrin-threatened pollen beetle meligethes aeneus: an in-depth proteomic study employing a transcriptome database. J Proteomics (2017) 150:281-9. doi: 10.1016/j.jprot.2016.09.016

28. Humphrey S, Azimifar S, Mann M. High-throughput phosphoproteomics reveals in vivo insulin signaling dynamics. Nat Biotechnol. (2015) 33:990-5. doi: 10.1038/nbt.3327

29. Cox J, Hein M, Luber C, Paron I, Nagaraj N, Mann M. Accurate proteomewide label-free quantification by delayed normalization and maximal peptide ratio extraction, termed MaxLFQ. Mol Cell Proteomics (2014) 13:2513-26. doi: 10.1074/mcp.M113.031591

30. Tyanova S, Temu T, Sinitcyn P, Carlson A, Hein M, Geiger T, et al. The Perseus computational platform for comprehensive analysis of (prote)omics data. Nat Methods (2016) 13:731-40. doi: 10.1038/nmeth.3901

31. Neckar J, Ostadal F, Kolar F. Myocardial infarct size-limiting effect of chronic hypoxia persists for five weeks of normoxic recovery. Phyysiol Res. (2004) 53:621-8.

32. Gemel J, Su Z, Gileles-Hillel A, Khalyfa A, Gozal D, Beyer EC. Intermittent hypoxia causes NOX2-dependent remodeling of atrial connexins. BMC Cell Biol. (2017) 18:1-10. doi: 10.1186/s12860-016-0117-5

33. Egan Benova T, Szeiffova Bacova B, Viczenczova C, Diez E, Barancik M, Tribulova N. Protection of cardiac cell-to-cell coupling attenuate myocardial remodeling and proarrhythmia induced by hypertension. Physiol Res. (2016) 65 (Suppl. 1):29-42.

34. Bacova B, Vinczenzova C, Zurmanova J, Kasparova D, Knezl V, Benova T, et al. Altered thyroid status affects myocardial expression of connexin-43 and susceptibility of rat heart to malignant arrhythmias that can be partially normalized by red palm oil intake. Histochem Cell Biol. (2017) 147:63-73. doi: 10.1007/s00418-016-1488-6 
35. Bartekova M, Simoncikova P, Fogarassyova M, Ivanova M, Okruhlicova L, Tribulova N, et al. Quercetin improves postischemic recovery of heart function in doxorubicin-treated rats and prevents doxorubicin-induced matrix metalloproteinase-2 activation and apoptosis induction. Int J Mol Sci. (2015) 16:8168-85. doi: 10.3390/ijms16048168

36. Kaprielian RR, Gunning M, Dupont E, Sheppard MN, Rothery SM, Underwood R, et al. Downregulation of immunodetectable connexin 43 and decreased gap junction size in the pathogenesis of chronic hibernation in the human left ventricle. Circulation (1998) 97:651-60. doi: 10.1161/01.CIR.97.7.651

37. Jansen JA, Van Veen TAB, De Jong S, Van Der Nagel R, Van Stuijvenberg $\mathrm{L}$, Driessen $\mathrm{H}$, et al. Reduced $\mathrm{Cx} 43$ expression triggers increased fibrosis due to enhanced fibroblast activity. Circulation (2012) 5:380-90. doi: 10.1161/CIRCEP.111.966580

38. Solan JL, Lampe PD. Specific Cx43 phosphorylation events regulate gap junction turnover in vivo. FEBS Lett. (2014) 588:1423-9. doi: 10.1016/j.febslet.2014.01.049.Specific

39. Solan JL, Lampe PD. Spatio-temporal regulation of connexin43 phosphorylation and gap junction dynamics. Biochim Biophys Acta Biomemb. (2018) 1860:83-90. doi: 10.1016/j.bbamem.2017.04.008

40. Axelsen LN, Calloe K, Nielsen MS. Managing the complexity of communication : regulation of gap junctions by post-translational modification. Front Pharmacol. (2013) 4:130. doi: 10.3389/fphar.2013.00130

41. Tenbroek EM, Lampe PD, Solan JL, Reynhout JK, Johnson RG. Ser364 of connexin43 and the upregulation of gap junction assembly by cAMP. J Cell Biol. (2001) 155:1307-18. doi: 10.1083/jcb.200102017

42. Solan JL, Marquez-Rosado L, Sorgen PL, Thornton PJ, Gafken PR, Lampe PD. Phosphorylation at S365 is a gatekeeper event that changes the structure of Cx43 and prevents down- regulation by PKC. J Cell Biol. (2007) 179:1301-9. doi: $10.1083 /$ jcb. 200707060

43. Kwak B, Jongsma H. Regulation of cardiac gap junction channel permeability and conductance by several phosphorylating conditions. Mol Cell Biochem. (1996) 157:93-9.

44. Cooper CD, Lampe PD. Casein Kinase 1 regulates Connexin-43 gap junction assembly. J Biol Chem. (2002) 277:44962-8. doi: 10.1074/jbc.M209427200

45. Lampe PD, Cooper CD, King TJ, Burt JM. Analysis of phosphorylation of connexin43 at s325/328/330 in normoxic and ischemic heart. J Cell Sci. (2006) 119:3435-42. doi: 10.1242/jcs.03089

46. Palatinus JA, Rhett JM, Gourdie RG. Enhanced PKCE mediated phosphorylation of connexin 43 at serine 368 by a carboxyl-terminal mimetic peptide is dependent on injury. Channels (2011) 5:236-40. doi: $10.4161 /$ chan.5.3.15834

47. Hlaváčková M, Kožichová K, Neckář J, Kolář F, Musters RJP, Novák F, et al. Up-regulation and redistribution of protein kinase C- $\delta$ in chronically hypoxic heart. Mol Cell Biochem. (2010) 345:271-82. doi: 10.1007/s11010-010-0581-8

48. Bao X, Reuss L, Altenberg GA. Regulation of purified and reconstituted connexin 43 hemichannels by protein kinase C-mediated phosphorylation of Serine 368. J Biol Chem. (2004) 279:20058-66. doi: 10.1074/jbc.M311137200

49. Lin H, Mitasikova M, Dlugosova K, Okruhlicova L, Imanaga I, Ogawa K, et al. Thyroid hormones suppress $\varepsilon$-PKC signalling, down-regulate connexin-43 and increase lethal arrhythmia susceptibility in non-diabetic and diabetic rat hearts. J Physiol Pharmacol. (2008) 59:271-85.

50. Cottrell GT, Lin R, Warn-Cramer BJ, Lau AF, Burt JM. Mechanism of $\mathrm{v}$-Src- and mitogen-activated protein kinase-induced reduction of gap junction communication. Am J Physiol Cell Physiol. (2003) 284:C511-20. doi: 10.1152/ajpcell.00214.2002

51. Lin R, Warn-cramer BJ, Kurata WE, Lau AF. Tyr265 disrupts gap junctional communication. J Cell Biol. (2001) 154:815-27. doi: 10.1083/jcb.200102027

52. Dunn CA, Su V, Lau AF, Lampe PD. Activation of Akt, not connexin 43 protein ubiquitination, regulates gap junction stability. J Biol Chem. (2012) 287:2600-7. doi: 10.1074/jbc.M111.276261

53. Dunn CA, Lampe PD. Injury-triggered Akt phosphorylation of Cx43: a ZO1-driven molecular switch that regulates gap junction size. J Cell Sci. (2014) 127:455-64. doi: 10.1242/jcs.142497

54. Kolar D, Gresikova M, Waskova-Arnostova P, Elsnicova B, Kohutova J, Hornikova D, et al. Adaptation to chronic continuous hypoxia potentiates Akt/HK2 anti-apoptotic pathway during brief myocardial ischemia/reperfusion insult. Mol Cell Biochem. (2017) 432:99-108. doi: 10.1007/s11010-017-3001-5

55. Beardslee MA, Lerner DL, Tadros PN, Laing JG, Beyer EC, Yamada KA, et al. Dephosphorylation and intracellular redistribution of ventricular connexin43 during electrical uncoupling induced by ischemia. Circ Res. (2000) 87:656-63.

56. Lerner DL, Yamada KA, Schuessler RB, Saffitz JE. Accelerated onset and increased incidence of ventricular arrhythmias induced by ischemia in $\mathrm{Cx} 43$ deficient mice. Circulation (2000) 101:547-52. doi: 10.1161/01.CIR.101.5.547

57. Peters NS, Coromilas J, Severs NJ, Wit AL. Disturbed connexin 43 gap junction distribution correlates with the location of reentrant circuits in the epicardial border zone of healing canine infarcts that cause ventricular tachycardia. Circulation (1997) 95:988-96.

58. Severs NJ. Gap junction remodeling and cardiac arrhythmogenesis: cause or coincidence? J Cell Mol Med. (2001) 5:355-66.

59. Seidel T, Salameh A, Dhein S. A simulation study of cellular hypertrophy and connexin lateralization in cardiac tissue. Biophys J. (2010) 99:2821-30. doi: 10.1016/j.bpj.2010.09.010

60. Adkins Y, Kelley DS. Mechanisms underlying the cardioprotective effects of omega-3 polyunsaturated fatty acids. J Nutri Biochem. (2010) 21:781-92. doi: 10.1016/j.jnutbio.2009.12.004

61. Endo J, Arita M. Cardioprotective mechanism of omega-3 polyunsaturated fatty acids. J Cardiol. (2016) 67:6-11. doi: 10.1016/j.jjcc.2015.08.002

62. Kang JX. Free, long-chain, polyunsaturated fatty acids reduce membrane electrical excitability in neonatal rat cardiac myocytes. Proc Natl Acad Sci USA. (1995) 92:3997-4001.

63. Leaf A, Kang JX, Xiao Y, Billman GE. Clinical prevention of sudden cardiac death by n-3 polyunsaturated fatty acids and mechanism of prevention of arrhythmias by n-3 fish oils. Circulation (2003) 107:2646-52. doi: 10.1161/01.CIR.0000069566.78305.33

64. Hallaq H, Smithl T, Leaf A. Modulation of dihydropyridine-sensitive calcium channels in heart cells by fish oil fatty acids. Proc Natl Acad Sci USA. (1992) 89:1760-4.

65. Ander B, Weber A, Rampersad P, Gilchrist J, Pierce G, Lukas A. Dietary flaxseed protects against ventricular fibrillation induced by ischemiareperfusion in normal and hypercholesterolemic rabbits. J Nutr. (2005) 134:3250-6. doi: 10.1093/jn/134.12.3250

66. Fischer R, Dechend R, Qadri F, Markovic M, Feldt S, Herse F, et al. Dietary n3 polyunsaturated fatty acids and direct renin inhibition improve electrical remodeling in a model of high human renin hypertension. Hypertension (2008) 51:540-6. doi: 10.1161/HYPERTENSIONAHA.107.103143

67. Radosinska J, Bacova B, Knezl V, Benova T, Zurmanova J, Soukup T, et al. Dietary omega-3 fatty acids attenuate myocardial arrhythmogenic factors and propensity of the heart to lethal arrhythmias in a rodent model of human essential hypertension. J Hypertens. (2013) 31:1876-85. doi: 10.1097/HJH.0b013e328362215d

68. Hlavackova M, Neckar J, Jezkova J, Balkova P, Stankova B, Novakova O, et al. Dietary polyunsaturated fatty acids alter myocardial protein kinase $\mathrm{C}$ expression and affect cardioprotection induced by chronic hypoxia. Exp Biol Med. (2007) 232:823-32.

Conflict of Interest Statement: The authors declare that the research was conducted in the absence of any commercial or financial relationships that could be construed as a potential conflict of interest.

The handling Editor declared a shared affiliation at the time of review, though no other collaboration, with several of the authors, JK, BE, OS, JJ, MV, PV, DH, ON and JZ.

Copyright (C) 2019 Kohutova, Elsnicova, Holzerova, Neckar, Sebesta, Jezkova, Vecka, Vebr, Hornikova, Szeiffova Bacova, Egan Benova, Hlavackova, Tribulova, Kolar, Novakova and Zurmanova. This is an open-access article distributed under the terms of the Creative Commons Attribution License (CC BY). The use, distribution or reproduction in other forums is permitted, provided the original author(s) and the copyright owner(s) are credited and that the original publication in this journal is cited, in accordance with accepted academic practice. No use, distribution or reproduction is permitted which does not comply with these terms. 